\title{
Study on teaching reform of the virtual instrument technology course based on training professional comprehensive ability
}

\author{
Chang Feng ${ }^{a}$, He Guangpu ${ }^{b}$,Tong Qiang,Zhu Jiaxiong,Zhou Dapeng,Fan Ling \\ School of Physics and Electronic Engineering of Leshan Normal University, China \\ a14987625@qq.com, b465071705@qq.com
}

\begin{abstract}
Keywords: The virtual instrument technology; teaching reform; the electronic and information engineering; professional comprehensive ability
\end{abstract}

\begin{abstract}
The virtual instrument technology is the current development trend of measurement technology and one of the required courses in electronic and information engineering. This article studies teaching reform that combines the theory teaching, professional courses- penetrated in experiment project and project-oriented teaching methods. New ideas are provided not only to improving teaching quality of the virtual instrument technology course, but also to improving professional comprehensive ability of the electronic and information engineering majors.
\end{abstract}

\section{Introduction}

The virtual instrument technology (VI) is the current development trend of measurement technology and one of the required courses in electronic and information engineering. This course that has the feature for training students' integrated design ability with software and hardware involves broad professional knowledge with strong applicability. The students who combine the theories of other courses with practice in this course, will be well prepared for their graduation projects, and have great job security in the future.

Adapting to social demand has been the train objective since the electronic and information engineering has been set up in our college. At the same time, many electronic information courses have been set up. The professional courses are in very close contact. Along with the increase of these courses, how to achieve the train objective of professional comprehensive ability through the whole electronic and information engineering knowledge, has become an important subject in professional teaching.

In order to improve the students' professional comprehensive ability and get the full scale development, we can start from such three training links as the theoretical research ability, practical ability and innovation ability. In foreign countries, the VI course runs through other courses being combined with theoretical teaching and experimental teaching. This create a connection between courses: On the one hand, the VI penetrates the other courses (e.g. measurement technology, sensor technology, electrical and electronic technology and so on). On the other hand, the theories of other courses(e.g. automatic control, digital communication, signal processing, image processing and so on) are introduced to the VI course.

\section{Teaching situation of virtual instrument technology course in our college.}

All the while, the VI course in our college has adopted a teaching mode that is a separation of theory and experiment in an independent lab, but there are many areas needs improvement.

Separation of theory and experiment, ignoring experiment against theory. More and more colleges began to set up VI course and VI experimental course, the purpose is to provide 
opportunities of theoretical study and innovation practice for student. It is consistent with our train objective of innovative talents. Not only does it let students develop creativity, but also is an important way to improve the students' ability and quality. Our VI course put emphasis on the theory teaching and ignores experiment, like other courses, the experiment arrangement depends on the plans of theory courses. For one thing, theory is separated from experiment, and the experiment course lags the schedule of theory course. Second, teachers did not design the elaborate experiment project, so that students think the experiment course is not important than theory course.

Course learning leans toward software. The concept of VI is put forward by American national instrument company, and LabVIEW, a design software of VI, that is also produced by NI company is widely used, so the VI courses in many colleges have a few hardware experiment just simply explaining how to use the LabVIEW software, Not excepting our college, the experimental projects contain a lot of validation experiments, and most of these experiments are too simple. So, The comprehensive experiments based on project, will have significant effects on the trainings of students' creative ability, practical ability, problem-solving ability and team work ability.

The unreasonable design and poor content. Our current experiment projects are divided into two parts. The front part is software experiment. The second part has a few hardware operations. The software experiment that is too simple and reflected in the use of single knowledge, has less comprehensive and causes a misallocation of knowledge point. There are also many problems in hardware operation. Students can only do the experiment according to content and steps by experiment instructor. Together with restrict function of the experimental device, the students' initiative and creativeness are limited.

\section{The reform of teaching system in VI course}

On the basis of the above description of VI course in our college, we have a new design for the course, which is a new teaching mode that combines the theory teaching, professional courses-penetrated in experiment project and project-oriented teaching methods. As Fig.1 shows, it is the combination of the three teaching methods (A for the theory teaching, B for professional courses- penetrated in experiment project, $C$ for project-oriented teaching methods). We can see these three teaching methods exist simultaneously in the whole teaching period.

\begin{tabular}{|c|c|c|c|}
\hline & 1 & 1 & \\
\hline & 3-10 weeks: & 11-16 weeks: & \\
\hline & The preparation for project-oriented & Designing & $\mathrm{C}$ \\
\hline & 1 & I proiect-oriented & \\
\hline & 1 & f project-onemted & \\
\hline & 1 & system & \\
\hline & 3-10 weeks: & 1 & \\
\hline & Learning software and doing exercises through & & B \\
\hline & professional courses- penetrated in experiment & project & \\
\hline & 1 & & \\
\hline 1-2 weeks: & I 3-16 weeks: The advanced technology and appl & lication of VI & \\
\hline The VI theory & & & $\boldsymbol{H}$ \\
\hline 1ine vi uneory & 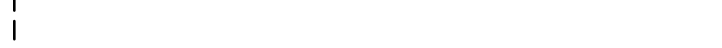 & & \\
\hline
\end{tabular}

Fig. 1 The combination time distribution of three teaching methods

Teachers' theory teaching. Although the teaching of VI emphasizes hands-on practice, but the theory of knowledge is just as important. Teachers' theory teaching will be throughout the semester as a rule to guide students. 
The basic knowledge of VI(the basic concept and theory of VI, the development and present situation of VI, the application and trend of VI, the software introduction of VI, the programming of LabVIEW etc) will be mainly taught in class at an earlier stage of the semester. According to the schedule and content in the late teaching, teachers can collect the new information from application and development of VI, and show these by multimedia to the students who can be familiar with the basic concept, principle, key technology, application of VI and not feel boring.

Professional courses- penetrated in experiment project. Developing project by exercises of LabVIEW and practices of professional courses- penetrated in experiment project through other existing electronic and information engineering knowledge, students can better consolidate the existing knowledge and put it into practice.

The other professional knowledge (such as automatic control, digital communication, signal processing, image processing and so on) is introduced into the VI course, being combined with the VI and the LabVIEW software programming technology. We call it professional coursespenetrated in experiment project that conforms to the teaching objects and contents of VI. According to the existing electronic and information engineering courses, experimental projects are designed as shown in Table 1. So we can see the comprehensive experimental projects keep up with teaching knowledge points of VI, and are interlocked step by step. These projects which are penetrated different courses embody the relationship between the current knowledge and teaching knowledge points. It affects students' ability to use the knowledge.

Table 1 List of professional courses- penetrated in experiment project

\begin{tabular}{l|l|l}
\hline Experimental Projects & Courses- penetrated & Teaching Knowledge Points \\
\hline $\begin{array}{l}\text { The design of digital } \\
\text { phase-locked loop }\end{array}$ & High Frequency Circuit & $\begin{array}{l}\text { Control structure } \\
\text { The for loop structure }\end{array}$ \\
\hline $\begin{array}{l}\text { Cymometer experiment } \\
\text { The design of arbitrary } \\
\text { waveform generator }\end{array}$ & Signals and Systems & $\begin{array}{l}\text { Sequence structure } \\
\text { Time node }\end{array}$ \\
\hline $\begin{array}{l}\text { The design of digital low-pass } \\
\text { filter }\end{array}$ & Digital Signal Processing & $\begin{array}{l}\text { Array } \\
\text { Chart and graphic }\end{array}$ \\
\hline $\begin{array}{l}\text { Modulation and demodulation } \\
\text { experiment }\end{array}$ & Digital Communication Principle & $\begin{array}{l}\text { Math and graphic } \\
\text { Signal processing and analysis }\end{array}$ \\
\hline $\begin{array}{l}\text { Temperature control system } \\
\text { Signal processing and analysis }\end{array}$ \\
\hline $\begin{array}{l}\text { Remote control system } \\
\text { Interpolation and fitting in } \\
\text { mathematical analysis }\end{array}$ & $\begin{array}{l}\text { SCMigital Image Processing } \\
\text { Automatic Control Principle }\end{array}$ & $\begin{array}{l}\text { Serial communication } \\
\text { String }\end{array}$ \\
\hline
\end{tabular}

In teaching process, teachers teach the teaching knowledge points, and then guide students to solve the related professional problems of other courses be penetrated using the VI technology. This is a process from introducing problems to analysing problems, and finally solving problems. In the concrete teaching, we take cymometer experiment as an example. Firstly, teacher introduces a practical problem: to measure a signal frequency. Secondly, teacher analyses a variety of issues with students, such as how to measure freguency, how to get the relationship that the freguency is equal to the cycle number of the measured signal in unit time, what mathematical basis or 
knowledge of Microcomputer Interface Technique to need. Finally, teacher guides students to solve problems by designing the VI system according to the knowledge (the sequence structure and the time node) learned in this lesson. Interactive teaching such as Microcomputer Interface Technique course being penetrated can gets students feel practicability of the VI technology. So as a student there is always the opportunity to be creative and give input into the graduation project, academic competition and innovation practice through a series of professional courses- penetrated in experiment project.

The application of project-oriented teaching method. The teaching methods with the combination of theory and practice can raise the students' abilities including practice ability, problem-solving ability and engineering ability, can also make a seamless transition from the school knowledge to the practical operations in work. The project-oriented teaching method takes the specific projects practicing as the main line, takes students as the main body and takes teachers' scientific guidance as the assistant teaching mean. This also called "the teaching method based on project". Within the whole teaching period, the teacher's theory teaching and project-oriented teaching complement each other.

The VI itself is a technology for application, and provides new ideas for the construction of the electronic system. If there are some projects following the steps such as data acquisition, data analysis, data display, data feedback, control, it will make students realize that how to construct a united electronic system more deeply.



Fig. 2 The flow chart of the system designing with project-oriented teaching method

In teaching process, students are divided into several groups with three in each, and there is a leader in each group. Teacher oversees the progress of the whole project mainly by asking the group leader. In the case of the design of temperature control system, witch contains all steps in designing of a electronic system, first of all, teacher puts forward the content of project: The design of a temperature control system, witch contains lower-machine and upper-computer. The lower-machine is a system of the temperature acquisition and control, adopting 51 series SCM as a core. The upper-computer, designed by LabVIEW and communicated with lower- machine by serial port, completes the real-time display and control of the temperature. Then as shown in Fig.2, there are several setps to realize the system. Students will finish the design oriented by project, based on team. At the same time, teacher provides relevant information and guidance, together with the assessment 
and incentive, promotes students' independent thinking, strengthens the teamwork and improves the ability to solve practical problems using the knowledge learned.

Such design not only relates to software development, but also needs to complete the design and debugging of the hardware, so the workload and the difficulty greatly increased. It could not be done only by existing class hours. There are several major solutions:

1) To increase class hours. With the increase of class hours for this course, the class hours of other courses must be reduced. This approach is less achievable.

2) To add comprehensive experiment project, especially hardware design. 1-2 items a semester, not too much.

3) By using the homework time after class and spare time. The traditional concept of the laboratory is expanded to the big-laboratory concept. This means that students can use the homework time after class and spare time to design and debug the system at the opening time of laboratory or somewhere else.

\section{Summary}

In conclusion, the new teaching reform that combines the theory teaching, professional coursespenetrated in experiment project and project-oriented teaching methods, can really make sure that the teaching theory and practice promote each other well, and make full use of the students' initiative in learning and creativity in practice. So the teaching, taking the VI course as a carrier, can improve the professional comprehensive ability of electronic information majors.

\section{Acknowledgements}

This work was financially supported by the Sichuan Higher Education Quality and Teaching Reform Project (2013-2016:393), the Teaching Reform Project of Leshan Normal University (2013:20) and the Teaching Reform Project of Leshan Normal University (JG13-YB17).

\section{References}

[1] Yanfang Fu, Penghui Tian, and Jing Ma: Research of Experiment Teaching based on Virtual Instrument Technology. ETT. Volume.6 . 455-457 (2010)

[2] Liu Lina, Zhang Baofeng, and Han Fangfang : The Application of Virtual Instrument in the Teaching Reform of the Professional Comprehensive Experiment. Education Teaching Forum. 122-124.23(2011).

[3] Dandan Yan, Wenlong $\mathrm{Xu}$, Bingqiao $\mathrm{Xu}$, and Guisheng Tao: Studies on Experiment of Measurement Technology Based on LabVIEW Platform. ETT. Volume.6 . 153-156 (2010)

[4] Xu Zheng: The Guidance of Virtual Instrument Technology and Experiment. National Instruments(2013)

[5] Information on http://www.ni.com/academic/zhs/ 